\title{
2012 Conference Theme Statement
}

\section{Representation and Renewal}

\author{
PROGRAM CO-CHAIRS: JOHN CAREY, DARTMOUTH COLLEGE. AND LYNN VAVRECK, UNIVERSITY OF \\ CALIFORNIA, LOS ANGELES
}

\section{APSA Annual Meeting, New Orleans, Louisiana}

August 30-September 2, 2012

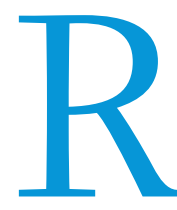

epresentation is ubiquitous to modern politics. In democratic and non-democratic settings alike, power is delegated to-or appropriated by-some to act in the name of others. Yet relationships of representation often go awry and are always and everywhere subject to skepticism, disillusionment, and calls for fundamental reform. Despite periodic calls for new modes of direct participation in decision-making, however, representation is inseparable from politics on a mass scale. For the 2012 meetings, we ask political scientists to reconsider the normative ideals we attach to representation, the factors that impede the realization of those ideals in practice, and the potential for representative relationships --whether preserved, reformed, or radically overhauled-to translate citizens' collective aspirations into effective public initiatives. We issue this call with an eye on renewal-of cities, economies, institutions, and relationships between the governed and those who govern.

In many longstanding democracies, public confidence in traditional representative institutions, such as political parties, trade unions, and legislatures, has experienced decades of steady decline. In regimes that have more recently professed a commitment to procedural democracy, the quality of representation is deeply suspect. The very premise that the public interest is best divined and advanced by elected representatives is challenged directly from China to Cuba to Saudi Arabia, and indirectly from Russia to Egypt, Venezuela to Ivory Coast, and Afghanistan to Zimbabwe. Even where adherence to representative government is widespread as in United States, its nuts and bolts warrant constant inspection and reevaluation. Should the Senate filibuster, or redistricting by partisan legislatures, or restrictions on corporate campaign finance, or census procedures that systematically under-count certain groups, survive? Would the quality of representation be improved if current practices were abandoned and reforged?

Representation is generally regarded as necessary when the size or diversity of the community, or the complexities of the decisions it faces, present obstacles to direct decision making. The principle of representation, however, raises a wide array of questions. What level of community attracts citizens' allegiance and identification? Do economic, technological, or geopolitical forces-many operating at the transnational level-affect the answers to these questions? For example, are the efficiencies promised by currency union sustainable politically under the current representative institutions of the European Union? Do the Andean states really share enough interests that a stronger supernational organization could gain traction? How ought the priorities of the IMF and the World Bank be determined? Can NATO articulate a common security agenda to which all its member states can subscribe? What interests are represented at summits called outside the rubrics of established international institutions-on climate change, for example? And of course, perennial debates over which states deserve representation on the United Nations Security Council only grow more pronounced with time. We urge political scientists to consider whether and how conflicting demands placed on representatives across different levels of government (supernational, national, and sub-national) and in different institutions can be resolved?

Representation at any level demands answers to the question of who should represent whom? Inclusiveness is a widely subscribed aspiration, but any representative arrangement implies that some groups and interests will get a seat at the table while others are left out. Where politics are contested on a playing field tilted by unequal distribution of resources --which is to say, almost everywhere --it is natural to ask whether the rules of representation ought to be adapted to mitigate the marginalization of disadvantaged groups. Fights over measures to ensure the representation of racial, ethnic, caste, religious, and linguistic minorities are more widespread now than ever, as are legal provisions to guarantee representation for a prevalent demographic majority, women. This is to say nothing of the lack of effort, from most governments, to amplify the voices of the most severely disadvantaged, whatever their characteristics. Do these efforts, could these efforts, improve representation? Do the ascriptive characteristics of representatives affect the types of policies they advocate, the decisions representative institutions produce, and the support they generate in the population? Answering such questions presents formidable measurement and methodological challenges, yet doing so is imperative if political science is to contribute to pressing debates about how to make formal political equality meaningful.

The expedience of making political decisions through representation inevitably comes with costs. To act on behalf of others, representatives require resources, which can be misappropriated and abused. And all representation entails some distance, some opacity between the representative and the represented. Corruption plagues many of these relationships and fuels demands to make information about the actions of representatives more transparent on matters ranging from allocation of public works among Indonesian villages, to voting in the parliaments of Argentina and Uganda, to sources of campaign finance in the United States, to the military and diplomatic communications targeted by WikiLeaks. 
Even Edmund Burke, who defended representatives' autonomy, encouraged them "to live in the strictest union, the closest correspondence, and the most unreserved communication with [their] constituents." Yet modern communications technologies force the questions: How close a correspondence? How unreserved the communications? Who should decide what information is useful and necessary, through what filters it should pass, and by what media it should be disseminated? And if malfeasance can be detected, what sanctions might be imposed on representatives to deter bad behavior?

Even if the matter of who sits at the table is resolved, and setting aside the abject abuse of power, representation is about making decisions, and there is a fundamental tension between inclusiveness and decisiveness. Consider some prominent examples from national elections in three quite different contexts. In early 2009, Barack Obama dismissed criticisms of his first stimulus package, noting that "I won the election." Within a year, however, he had a keener appreciation for the ability of American representative institutions to put the brakes on his apparent mandate. Another year later Republicans were claiming a midterm election mandate of their own, yet a lame duck session of Congress at the end of 2010 went on to pass landmark legislation on an array of policies. Observers of American politics swung from narratives of juggernaut, to morass, to partisan compromise, seemingly astonished at every turn. Meanwhile, in early 2010, an alliance advocating secularism and drawing support from across various confessions won Iraq's national election, yet was unable to form a viable government. Almost a year passed before a new coalition, composed of uneasy allies and former adversaries, and resting on a fractious and uncertain parliamentary majority, could put a cabinet in place. Finally, in the UK, the 2010 election yielded a hung parliament with no clear winner, but quickly produced a coalition of unfamiliar bedfellows that moved to adopt major policy changes that deviated from both parties' platforms.

Each of these cases pits the ideals of decisiveness against rules designed to protect political minorities. And a common refrain from political observers is that representatives are so polarized in their views that, rather than fostering compromise, minority protections guarantee gridlock. Even faithful representatives, in short, face the perennial dilemma of how much intransigence is too much, when to compromise and when to hold out. For political scientists, the questions that follow are what factors encourage polarization among representatives and what factors conciliation? At what point does compromise entail betrayal? Is there a point at which minority representation is counterproductive? If so, what determines where that point is, and how it could be identified across different historical, cultural, geopolitical, and social contexts?

For the 2012 meetings, we encourage APSA members to address foundational questions about representation. We call for research that asks what representative relationships can and cannot achieve, how they might be renewed, reformed, or retooled to achieve those ends, and under what contexts political goals might be best served through direct or participatory democracy rather than through the mediation of representatives. We encourage division heads to reflect on how the most innovative work in their subfields can inform debates around this theme, and we invite them to collaborate with us in designing panels and roundtable discussions that speak to issues highlighted by this theme. We also welcome creative efforts to promote work across subfields and divisions. 